\title{
PERSISTENCIA DE LA TRADICIÓN PESCADORA RECOLECTORA EN LA COSTA DE ARICA: IDENTIFICACIÓN DE RASGOS CULTURALES Y DISCUSIÓN SOBRE SU ALCANCE EN EL CONTEXTO DE LAS POBLACIONES AGRÍCOLAS TEMPRANAS*
}

\author{
PERSISTENCE OF THE FISHING-COLLECTING TRADITION ON ARICA \\ COAST: IDENTIFICATION OF CULTURAL FEATURES AND DISCUSSION ON \\ THE REACH IN THE CONTEXT OF EARLY AGRICULTURAL SOCIETIES
}

\author{
Iván Muñoz Ovalle
}

\begin{abstract}
El estudio de las poblaciones en tránsito hacia la agricultura en los valles costeros de Arica arroja evidencias de una fuerte presencia de rasgos tecnológicos vinculados al período Arcaico; el trabajo de la piedra, el hueso, las conchas y el uso de fibras vegetales denotan la persistencia de estos contextos en el tiempo, a pesar de las transformaciones sociales y económicas producidas durante el proceso inicial agrícola. Dicha persistencia vista a través de la materialidad nos hace pensar en la importancia que tuvieron las tempranas poblaciones aldeanas locales en el desarrollo de las estrategias organizativas, contrastando con una presencia menor de rasgos procedentes de otras áreas culturales como la puna, las que habrían influenciado los valles costeros como Azapa durante el período Formativo. La información cultural con que se discute la presencia de la tradición pescadora recolectora en el contexto de los inicios de la tradición agrícola aldeana corresponde a evidencias obtenidas de áreas domésticas y funerarias vinculadas a ocupaciones precerámicas de la costa de Arica, las que fueron contrastadas con materialidad proveniente de poblaciones de túmulos y pisos habitacionales vinculada al período Formativo del valle de Azapa. La discusión de ambas materialidades nos da una visión interesante en el sentido que, por un lado, observamos la presencia de indicadores novedosos dentro del bagaje de estas poblaciones en tránsito hacia la agricultura; sin embargo, y quizás en un contexto de mayor frecuencia, registramos la presencia de artefactos que caracterizan a las poblaciones arcaicas costeras, remarcando, por lo tanto, una continuidad cultural que no se pierde con los cambios producidos con la economía agrícola.
\end{abstract}

Palabras claves: pescadores-recolectores, período Arcaico, rasgos culturales, sociedades formativas.

The study of in transit population towards agriculture on the coastal valleys of Arica shows evidence of a strong presence of technological features linked to the Archaic Period. Despite the social and economical transformations produced during the initial agricultural process, the work on stone, bone and the use of vegetable fiber donote the persistency of these contexts over time. Seen through materiality, such persistency makes us think about the importance that local populations had on the organizational strategies which established the early village populations, contrasting with a minor presence of the features from other cultural areas such as the puna which had probably affected coastal valleys like Azapa during the Formative Period. The cultural information discusses the presence of the fishing-collecting tradition in the context of the beginning of the village's agricultural tradition correspond to evidence obtained from domestic and funeral areas linked to preceramic settlement in Arica's coast, which were contrasted to materiality from populations from tumulus and housing floors linked to the formative period of Azapa Valley. The discussion of both materialities gives us an interesting vision in the sense of that, on one side, we see the presence of original indicators inside the cultural knowledge of these in transit populations towards agriculture, however, and maybe in a more frequent context we register the presence of artifacts typical of these archais coastal populations; thus emphasizing a cultural continuity which is not lost with the agricultural economy changes.

Key words: Fishing-collecting, Archaic Period, cultural features, formative societies.

La importancia de las sociedades arcaicas costeras en el desarrollo de la cultura andina se establece en su profunda temporalidad, su adaptación geográfica, en la complejidad de sus prácticas mortuorias y en la construcción de edificios ceremoniales. Desde el punto de vista social, Kaulicke y Dillehay (1999:13)

* Un texto preliminar de este artículo fue presentado en el 53 Congreso Internacional de Americanistas, Simposio "El período Arcaico en los Andes Sur Centrales: Tradiciones culturales e innovaciones tecnológicas", Ciudad de México, 19 al 24 de julio de 2009. Este manuscrito fue evaluado por investigadores externos y editado por Luis Flores Blanco y Mark S. Aldenderfer, en su calidad de editores invitados de la Revista.

1 Departamento de Antropología, Universidad de Tarapacá, Arica, Chile.imunoz@uta.cl 
plantean que la génesis de algunas problemáticas sociales como las confrontaciones, el concepto de propiedad o territorialidad, las prácticas religiosas y rituales tendrían sus orígenes en este período de pesca, caza y recolección, constituyéndose posteriormente en dinámicas fundamentales en el desenvolvimiento y desarrollo de las poblaciones andinas. Desde el punto de vista cronológico, cubren todo el espacio temporal que va desde las primeras evidencias del hombre en América, período Paleoindio, hasta el inicio del período Formativo, dividiéndose este proceso en tres períodos: Arcaico Temprano (10.000 al 8.500 a.p.), Arcaico Medio (8.500 al 5.000 a.p.) y Arcaico Tardío (5.000 al 3.500 a.p.).

En relación con el poblamiento arcaico de la costa de Arica, éste habría aprovechado las bondades del clima (cálido y estacional), sin importantes cambios entre la estación veraniega y la estación invernal; por otro lado, el mar de Arica es recorrido por la Corriente de Humboldt, que se caracteriza por aguas de baja temperatura, ricas en oxígeno y plancton, y por lo tanto ricas en minerales y materias orgánicas que hicieron posible la existencia de una numerosa y variada fauna marina (Sagredo et al. 1998). Ambas características -clima estacional y riqueza marina- permitieron la sobrevivencia y desarrollo de las tempranas comunidades de pescadores y recolectores. Sin embargo, desde el período Arcaico Temprano observamos desplazamientos de grupos humanos desde la costa hacia los valles interiores con el propósito de explotar recursos que les permitiesen complementar la economía costera; este esquema de movilidad-vertical y horizontal-al parecer constituyó el modo normal de desplazamiento de los grupos arcaicos que poblaron el litoral del norte de Chile. Núñez (1983) al formular el proceso de adaptación a la costa plantea que alrededor del 8.000 a.p., como consecuencia de trastornos climáticos (sequedad ambiental), se habrían producido desplazamientos de cazadores altoandinos a valles y quebradas bajas para luego acceder a la costa, concentrándose estos tempranos grupos en las desembocaduras de ríos, espacios de diversidad de recursos, como Camarones y San José. Una vez establecidas en la costa, estas poblaciones habrían organizado desplazamientos humanos hacia los valles interiores con el propósito de obtener recursos complementarios (Núñez 1979, 1989). Algunos ejemplos de esta interacción lo observamos en las ocupaciones arcaicas de la costa de Arica y Camarones como Acha-2 (Muñoz 1993) y Conanoxa Wb (Schiappacasse et al. 1993) y en la costa sur peruana en los asentamientos de Yara, Kilómetro 4 y Quebrada los Burros (Lavallée et al. 1999; Rasmussen 1998; Wise 1999); los hallazgos señalan un uso reiterado de las fibras vegetales para la confección de la cultura material, el frecuente trabajo de la piedra, concha y hueso para la confección de instrumentos de caza, pesca y recolección, además del uso de estos recursos en la construcción de sus campamentos. El espacio residencial lo constituían campamentos conformados por recintos de construcción simple. La materia prima utilizada para construir dichos recintos fueron huesos de mamíferos marinos y maderos de pacae (Inga feuillei) utilizados como soporte de techo y totora y pieles de mamíferos marinos para confeccionar toldos y techumbres.

Desde el punto de vista de su organización, se trataría de poblaciones costeras que explotan temporalmente los valles, por lo tanto los ejes conductivos que organizaron la economía se habrían situado en la costa (litoral) donde estaban los campamentos bases como Macarena en la desembocadura del río Lluta; Morro, en la desembocadura del río San José; Playa Miller, Quiani y la Capilla en la costa sur de Arica. Respecto a la conquista del mar, un artefacto fundamental lo constituyó la elaboración del anzuelo, el que según Llagostera (1979) les permitió obtener un recurso permanente sin agotar la fauna ictiológica. Un consumo alto de pescado en la dieta de estos pescadores lo señala Aufderheide (1993) a través del estudio de la reconstrucción química de la dieta del poblador de Acha-2. De acuerdo con los porcentajes este sería: vegetal no maíz $8,3 \%$, marinos $81,5 \%$ y carne terrestre $10,2 \%$. Aufderheide plantea que entre los productos marinos pudieron haberse consumido lobos marinos (Otaria jubata) y peces de aguas profundas. La obtención de estos peces, a través de la caza submarina, tal vez habría sido la causa de la exostosis en el conducto auditivo externo, una patología laboral diagnosticada en los individuos analizados (Arriaza 2003). En lo que respecta al sitio Morro-1, Standen (1991:266) señala que los alimentos más comunes eran moluscos, pescado, aves y lobo marino. Una situación similar se encontró en Quiani 1 y 9 (Bird 1943; Muñoz y Chacama 1982) donde los recursos más utilizados fueron el lobo de mar, moluscos, aves marinas y peces. Finalmente, otros estudios que refuerzan este planteamiento lo señalan Reinhard y Dendy (1994), quienes analizaron el contenido intestinal de momias Chinchorro tardías, revelando 
una dependencia marítima; señalan además que varias de las momias tenían ovas de parásitos intestinales debido al consumo de pescado crudo. Esto demuestra que no cocinaban, o que no cocían bien sus productos, al menos el pescado.

Para lograr esta base dietética Bittmann y Munizaga (1976) plantean que el reconocimiento de los hábitats marinos por parte de las poblaciones arcaicas fue fundamental; para tal efecto señalan la importancia de las playas arenosas y roqueríos, donde obtuvieron los recursos de pesca y recolección de moluscos; las desembocaduras de ríos, donde recolectaron plantas y cazaron mamíferos de menor tamaño (roedores); las aguadas del litoral como las que se ubican en la desembocadura del río San José y en quebrada Quiani, que habrían permitido tener acceso a recursos hídricos cercanos a los lugares de asentamiento. Otros recursos correspondieron a las aves marinas, las que proveyeron de plumas, pieles y huesos para la elaboración de artefactos y también como alimento. En esta perspectiva, el desierto costero ariqueño, incluidos los valles que desembocan en el Pacífico, fue mucho menos inhóspito de lo que aparece a primera vista, pues ofreció una gran cantidad de recursos naturales, especialmente de flora y fauna a lo largo de las estaciones del año.

\section{Cultura Material}

Las sociedades tradicionales no conciben a la cultura material como simples artefactos utilitarios, los objetos son partes de las personas, participan de la vida de ellas, por la tanto su importancia reside en su significado y su historia particular, de tal manera, los artefactos tienen memorias e historia de vida (Ingold 2000).

En arqueología diversos autores como Conkey y Spector (1984) han señalado la importancia del estudio de la cultura material en la caracterización de los grupos humanos; plantean que los restos materiales contienen una serie de mensajes, interpretables mediante el análisis arqueológico. Lumbreras (1981), por su parte, señala que la arqueología como ciencia social infiere, a partir de los restos culturales, las relaciones sociales de producción. Shanks y Tilley (1987) plantean que la cultura material está involucrada en el mundo social, es un medio importante en la percepción y conocimiento del mundo. Olsen (2003), a su vez, señala que la cultura material puede ser enfocada desde la arqueología como un texto con múltiples interpretaciones de la sociedad. Giddens (1990) plantea que el significado social de los grupos humanos se puede interpretar en base a los objetos culturales, en tanto estos introducen mediciones específicas en la relación cultura-lenguaje-comunicación. Acuto (2008) reflexiona en el sentido que la cultura material tiene un rol activo en el proceso social, da forma y reproduce prácticas y relaciones sociales en contextos históricos y culturales específicos, contribuye activamente a la conformación y reproducción de ciertas relaciones sociales, identidades ideológicas y modos específicos de categorizar y clasificar al mundo y a la realidad.

De lo anteriormente señalado, podemos observar múltiples entradas de estudios para la interpretación de la cultura material en el contexto social de las poblaciones del pasado; ahora bien, para efectos de nuestro estudio, la materialidad se enfoca mostrando un uso milenario de ciertos recursos naturales propios del desierto que fueron transformados por las poblaciones de pescadores en artefactos con el objetivo de lograr una adaptación al medio, por lo tanto, si bien en el análisis y discusión de los contextos (gráficos) hay un enfoque funcionalista de dicha materialidad, en el sentido de que los objetos los hemos visto como herramientas útiles y funcionales para determinar fines, en las conclusiones se discuten aspectos donde el paisaje y la memoria fueron la base sobre el cual se cimentó la identidad de las poblaciones tempranas de la costa de Arica.

Nuestro planteamiento teórico apunta a valorar la relación dialéctica entre los objetos y quienes la usaban, en este caso las poblaciones Chinchorro, y el sentido de lugar, la costa y valles desérticos, del cual dichas poblaciones se sintieron emocionalmente conectadas.

\section{Antecedentes}

Investigaciones desarrolladas por Núñez (1969, 1979, 1983, 1989) señalan una estrecha relación de los grupos costeros en la formación de las sociedades agrícolas tempranas; el uso de materias primas y la presencia de tecnologías para la pesca y caza marina son claros testimonios de una continuidad de rasgos culturales que van a permanecer en el tiempo. Este planteamiento de Núñez ha sido corroborado por Santoro $(1980,1982)$ y Muñoz $(1980,2004)$, quienes han señalado la importancia 
de las poblaciones costeras en el contexto de las poblaciones en tránsito hacia la agricultura. Ahora bien, el soporte cultural sobre el cual se asentaron las poblaciones agrícolas tempranas según Standen et al. (2004) habría sido consecuencia de un proceso de evolución y desarrollo local por parte de los grupos arcaicocosteros.

Desde el punto de vista biológico, Sutter (1994, 2006) al analizar la dinámica poblacional de las tempranas poblaciones de la costa de Arica postula que estas fueron grupos cerrados biológicamente, con rasgos génicos que indicarían una reproducción dentro de la misma población; por lo tanto, desde el punto de vista cultural esto habría producido una fuerte tradición que perduró por miles de años.

Sin embargo, un proceso más abierto, relacionado con contactos y flujos poblacionales de otras áreas, lo plantean Rivera y Rothhammer (1986), Moraga et al. (2001), Rothhammer et al. (2009), al señalar que el proceso de transformación cultural de las poblaciones prehistóricas costeras y vallunas del norte de Chile podría explicarse parcialmente por flujos migracionales originados en la vertiente oriental de los Andes y/o en las tierras bajas tropicales durante el período Arcaico Tardío y Formativo Temprano. Durante el período Formativo estas vinculaciones, según Rivera (1976), se traducirían en el posicionamiento de colonias altiplánicas en los valles costeros, por lo tanto, los grupos en tránsito a la agricultura habrían tenido un soporte cultural vinculado a tierras altas, mencionándose entre otras poblaciones a Pukara, Chiripa y Wankarani.

\section{Objetivos y Método}

De la discusión generada en el capítulo Antecedentes se desprende nuestro objetivo general, que apunta a identificar el aporte que las sociedades arcaicas costeras hicieron a las sociedades agrícolas tempranas enclavadas en los sectores bajos del valle de Azapa. De ello, dos objetivos específicos, (a) describir las materias primas y artefactos elaborados durante el período Arcaico y (b) identificar la continuidad de los artefactos del período Arcaico,

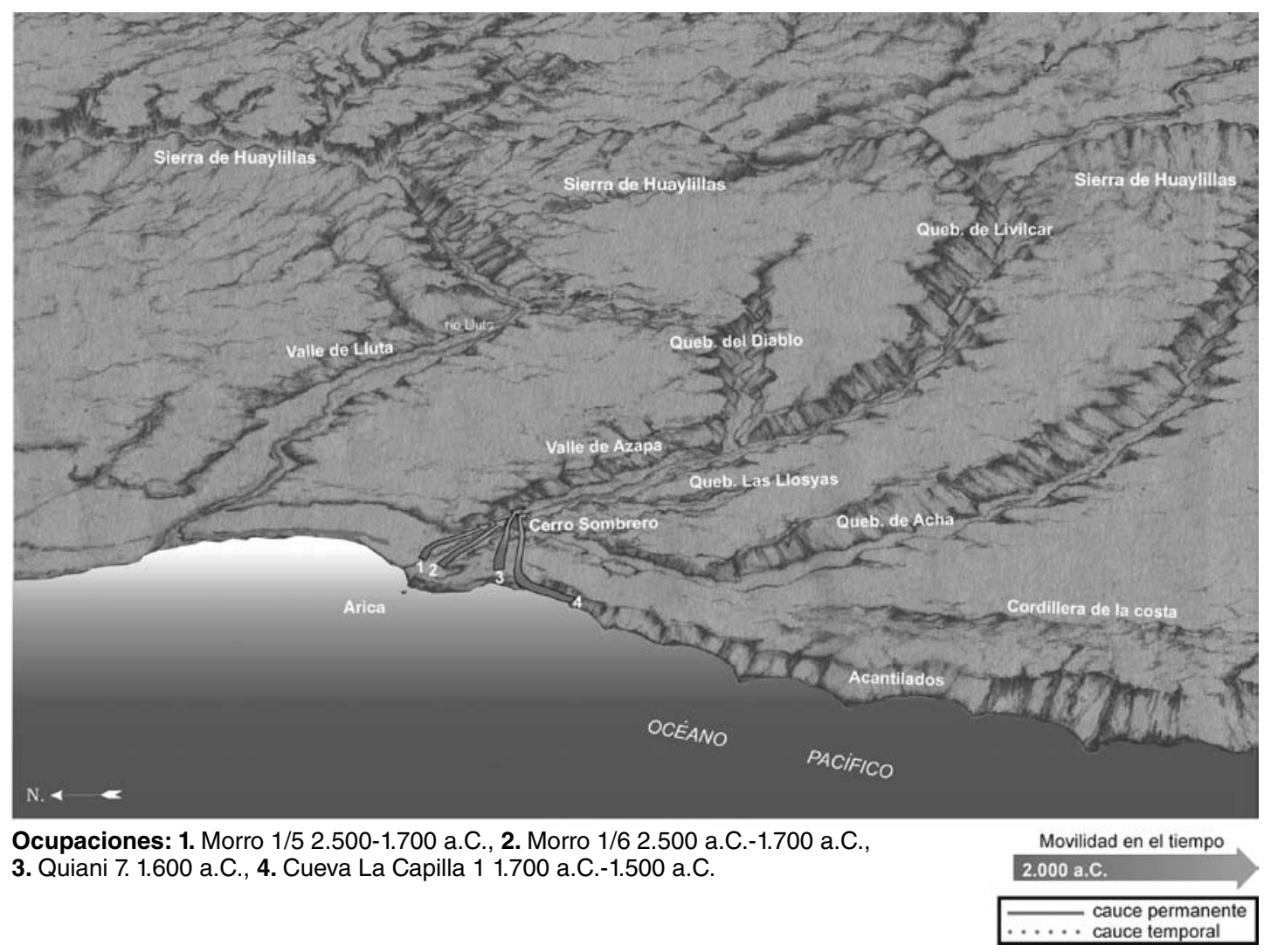

Figura 1. Ocupación de la franja costera de Arica y dominio del valle de Azapa durante el periodo Arcaico Tardío. Occupation of Arica's coastal edge and dominion of Azapa Valley during Late Archaic Period. 
presentes en los tempranos asentamientos de túmulos del período Formativo, permitirán conocer en su real dimensión la importancia de los pescadores durante el proceso agrícola temprano.

Desde el punto de vista metodológico, la información de las poblaciones arcaicas costeras fue obtenida de las investigaciones de campo realizadas por el autor de este artículo, materiales hallados en las colecciones del Museo San Miguel de Azapa, además de apuntes y material bibliográfico, donde se describen una serie de sitios vinculados a basurales, campamentos y cementerios excavados en la costa de Arica: Acha 2 (Muñoz y Chacama 1993), Acha 3 (Standen y Santoro 2004), Morro 1, 1-5 y 1/6 (Allison et al. 1984; Focacci y Chacón 1989; Guillén 1997; Llagostera 2003; Muñoz y Arriaza 2006; Rivera 1995; Standen 1991), Quiani 1 (Bird 1943), Quiani 9 (Muñoz y Chacama 1982), Quiani 7 (Dauelsberg 1974), Playa Miller 7 y 8 (Focacci 1974 y Álvarez 1969) y La Capilla 1 (Muñoz y Chacama 1982) (Figura 1). En la clasificación de este material se consideró como unidad base la materia prima, para posteriormente describir los distintos rasgos culturales que se desprenden de la elaboración de los recursos naturales.
En lo que respecta al estudio descriptivo de la materialidad esta información la registramos de las referencias bibliográficas anteriormente señaladas, y por lo tanto el análisis y discusión de dicha materialidad se basa en la información que proyectan los gráficos. En cuanto a éstos, el eje horizontal es indicador de la materia prima y el eje vertical (presencia) es indicador del número de rasgos culturales (objetos) por materia prima.

En el caso de las poblaciones agrícolas tempranas su estudio se centró en el sector bajo del valle de Azapa, los registros provienen de los cementerios de túmulos: AZ-70, túmulo 7, AZ-12, túmulo 1, AZ-122 (Muñoz 2004), AZ-67, túmulo 1 (Figura 2). Otros registros fueron tomados de los pisos habitacionales de AZ-115 (Muñoz 2004). La descripción de los materiales utilizados en la construcción de los montículos, así como el hallazgo de tumbas y ofrendas los hemos registrado por materia prima, lo cual nos ha llevado a comparar la larga data de algunos objetos vinculada a la tradición de pescadores-recolectores.

En cuanto al análisis y resultados esto se desarrolló a partir de la información arrojada por los gráficos, analizando la importancia de cada rasgo

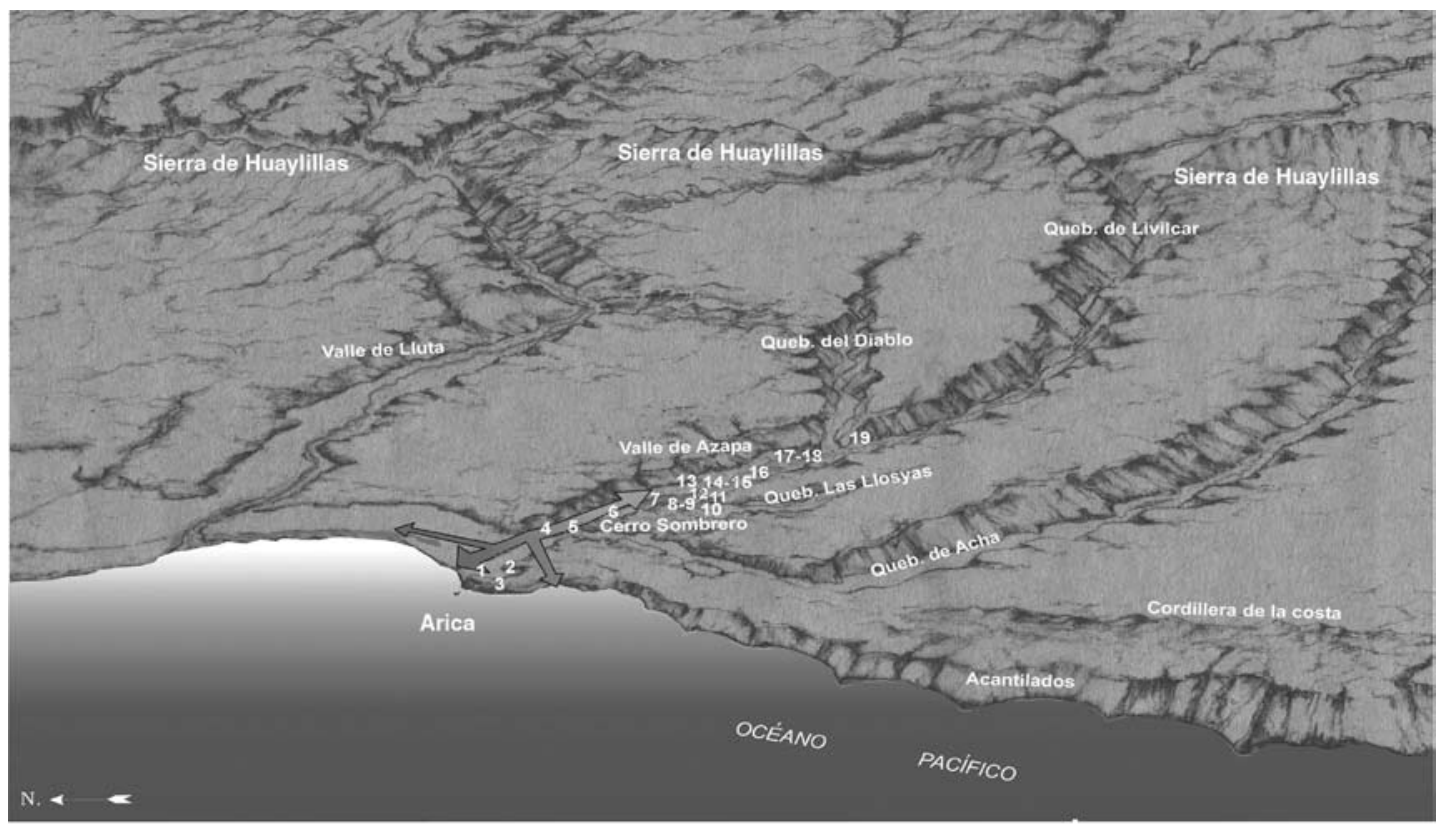

Asentamientos: 1. Morro 2/2, 2. Morro 3, 3. PLM 7, 4. Az-24, 5. Az-21, 6. Az-22, 7. Az-146, 8. Az-86, 9. Az-17, 10. Az-122, 11. Az-14, 12. Az-80, 13. Az-147, 14-15. Az-142, 16. Az-89, 17. Az-70, 18. Az-71, 19. Az-67.

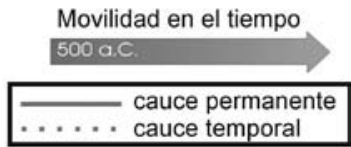

Figura 2. Ocupaciones del periodo Formativo, sector bajo del valle de Azapa y sector sur de la costa de Arica. Formative Period occupations, low area of Azapa Valley and south area of Arica's coast. 


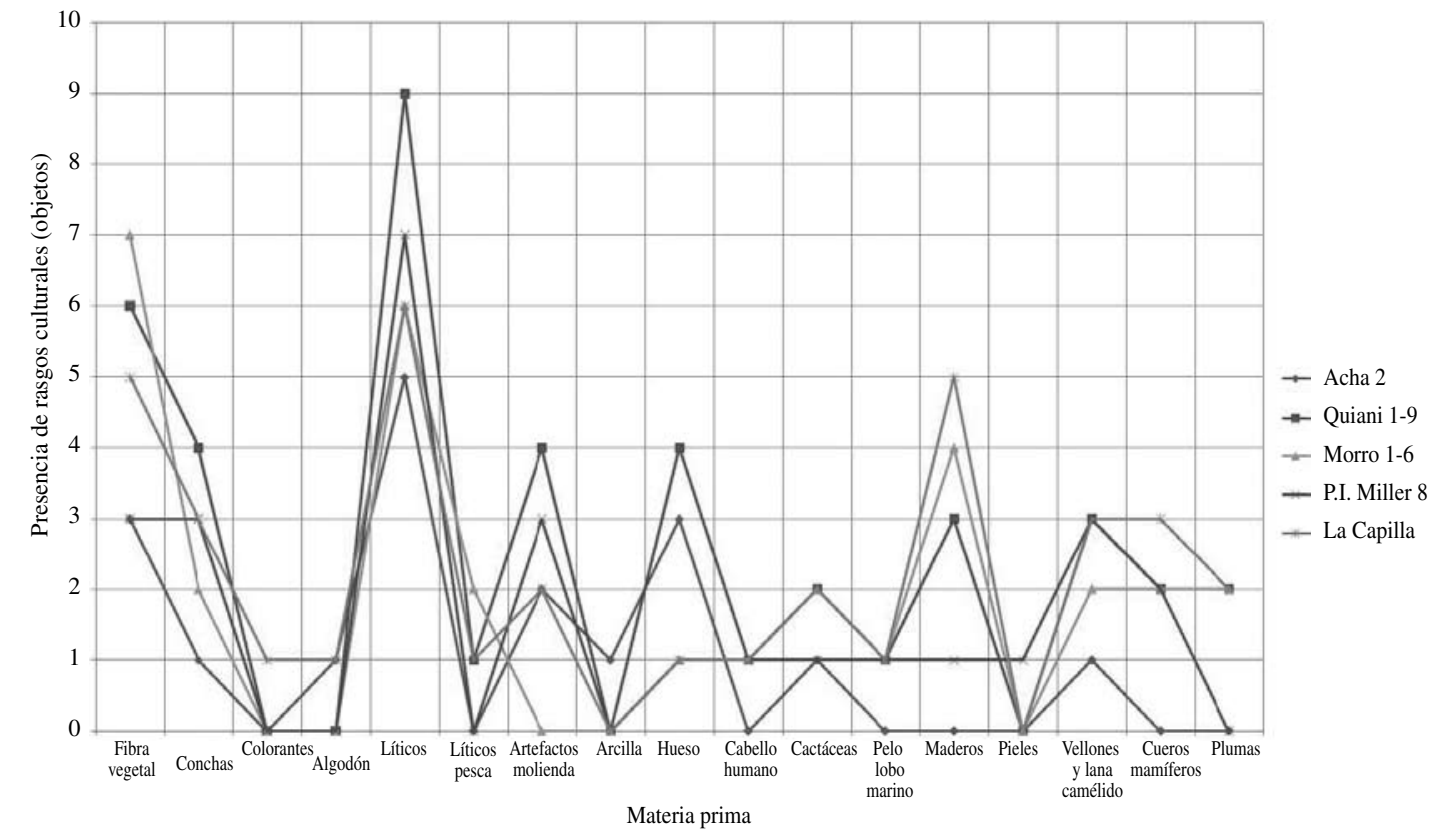

Figura 3. Presencia de rasgos culturales en poblaciones arcaicas.

Presence of cultural characteristics in archaic populations.

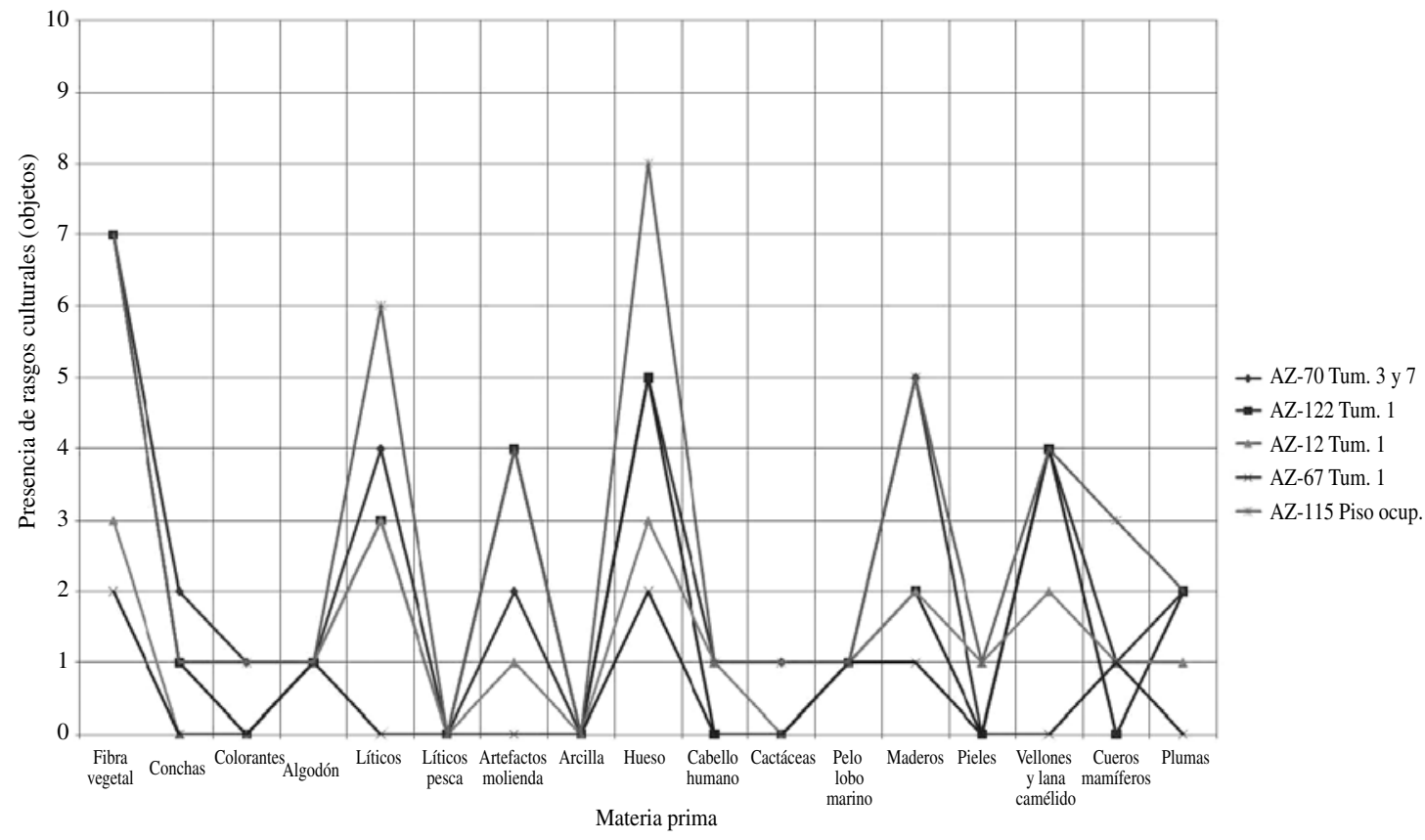

Figura 4. Presencia de rasgos culturales en poblaciones formativas.

Presence of cultural characteristics in formative populations. 


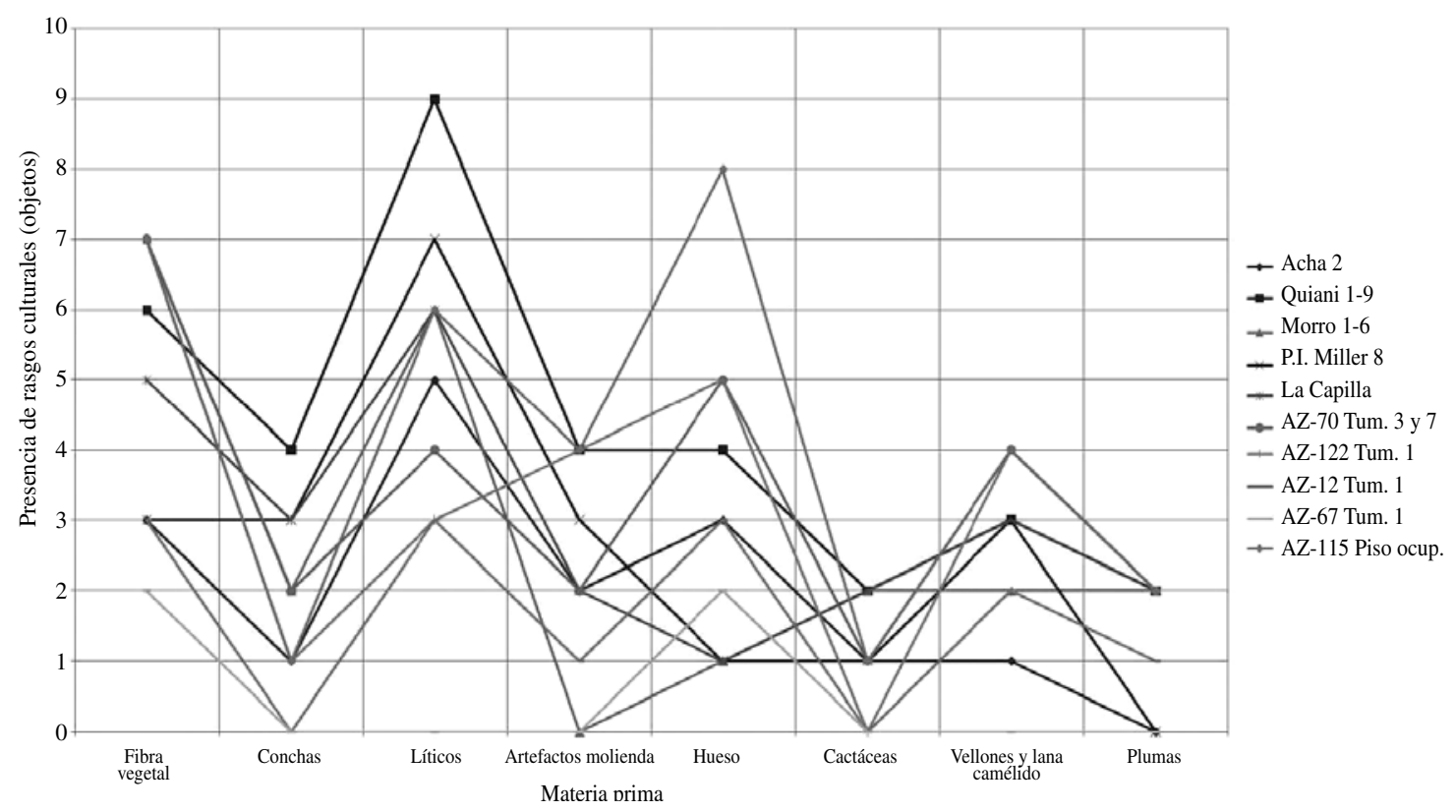

Figura 5. Continuidad de rasgos culturales desde el periodo Arcaico al período Formativo. Continuity of cultural characteristics from Archaic to Formative Period.

cultural en el tiempo, tanto en las poblaciones arcaicas costeras como en las poblaciones formativas de Azapa (Figuras 3 y 4). Finalmente se contrastan los rasgos culturales más representativos por sitio, en un gráfico que nos muestra su presencia en el tiempo (Figura 5).

\section{Análisis y Resultados}

En la Figura 3, relacionado con las poblaciones arcaicas de la costa de Arica, observamos que los objetos manufacturados en fibra vegetal, piedra, hueso y concha son los que presentan mayor frecuencia de rasgos; su uso en distintas funciones, doméstica y ceremonial, sugiere que estos recursos fueron fundamentales en el quehacer diario de los pescadores arcaicos (Figuras 6 a la 13). De los objetos manufacturados en fibra vegetal sobresale el trabajo en totora y junquillo, con los que confeccionaron redes, cordelería y sedales, estos últimos usados como lienzas para pescar. Otras piezas de vestir de uso cotidiano fueron faldellines y cobertores púbicos. Como ofrendas existen una serie de manufacturas hechas en fibra vegetal, entre ellas, las envolturas de fibra vegetal (algunas revestidas superficialmente con plumas de aves marinas) y la cestería, esta última con formas de platos de paredes extendidas que comienzan a confeccionarse a partir del período Arcaico Tardío. También se han hallado espinas de cactáceas, con las que confeccionaron anzuelos, cuyos hallazgos son frecuentes en los estratos precerámicos de los conchales de Quiani. Con las ramas de árboles se confeccionaron pequeñas brochitas, las que entre otras funciones sirvieron para limpiar y pintar las momias. En los entierros del período Arcaico fueron halladas una variedad de cuerdas cuyos diámetros van desde 1 a $3 \mathrm{~mm}$, estos hilados fueron torcidos en $\mathrm{Z}$ y después en $\mathrm{S}$, se utilizaron en el armazón interno de las momias Chinchorro, también fueron usadas para embarrilar los maderos longitudinales adosados a los huesos largos del cuerpo de las momias (Arriaza 1994). En los entierros de la tradición Chinchorro, la mayoría de los cuerpos se encuentran envueltos en mortajas de esteras de fibra vegetal. La técnica más común para confeccionar estas esteras fue el "twining" (Schiappacasse y Niemeyer 1984:65; Standen 1991) que consistía en amarrar las fibras vegetales elaborando finas esteras, algunas tienen diseños escalonados de colores, ya sea pintados o bordados con lana, pero por lo general las esteras eran del color natural de la fibra. También se utilizaban fragmentos de esteras para rellenar o reforzar internamente las 


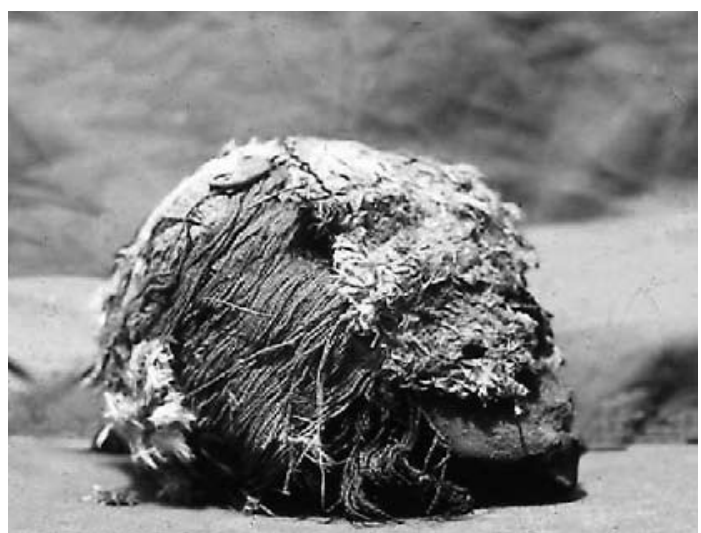

Figura 6. Cráneo enturbantado con piel y plumas, sitio PL. Miller 7.

Skull in a feather and fur turban, site PL. Miller 7.

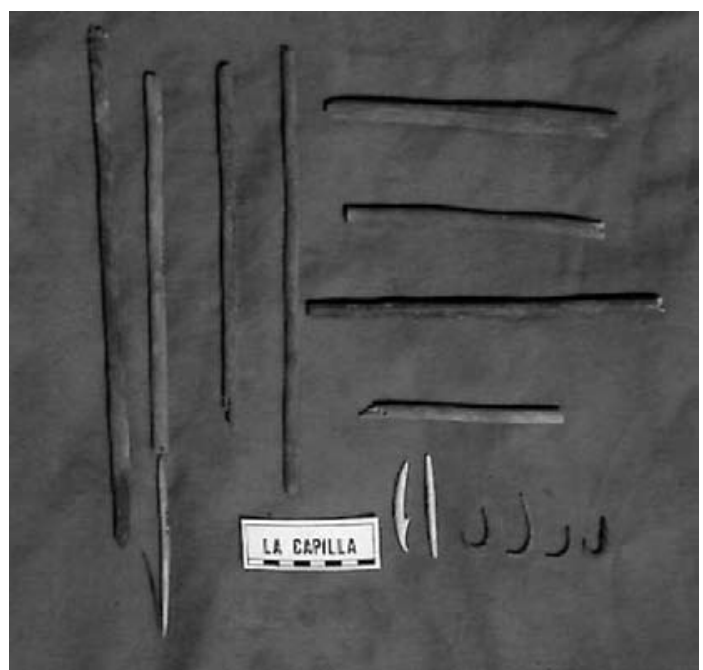

Figura 7. Tecnología para la pesca, sitio cueva La Capilla. Fishing technology, site La Capilla cave.

momias preparadas, es frecuente hallar haces de fibra vegetal utilizadas como relleno, especialmente en las cavidades craneanas y torácicas. Otra planta utilizada frecuentemente por los pescadores arcaicos fue el algodón, su uso fue para elaborar cordelería, con la cual se preparaban las esteras de totora que cubrían los cuerpos.

Respecto al material lítico los objetos más frecuentes fueron hechos en calcedonia (rocas silíceas y cuarzo) confeccionando puntas, cuchillos, raspadores y raederas, entre otros artefactos. Las puntas diagnósticas se caracterizan por tener formas lanceoladas, algunas llevan pedúnculos. Los cuchillos tienen forma semialunada, de base redonda, presentan un fino trabajo a presión en sus caras laterales. Otro

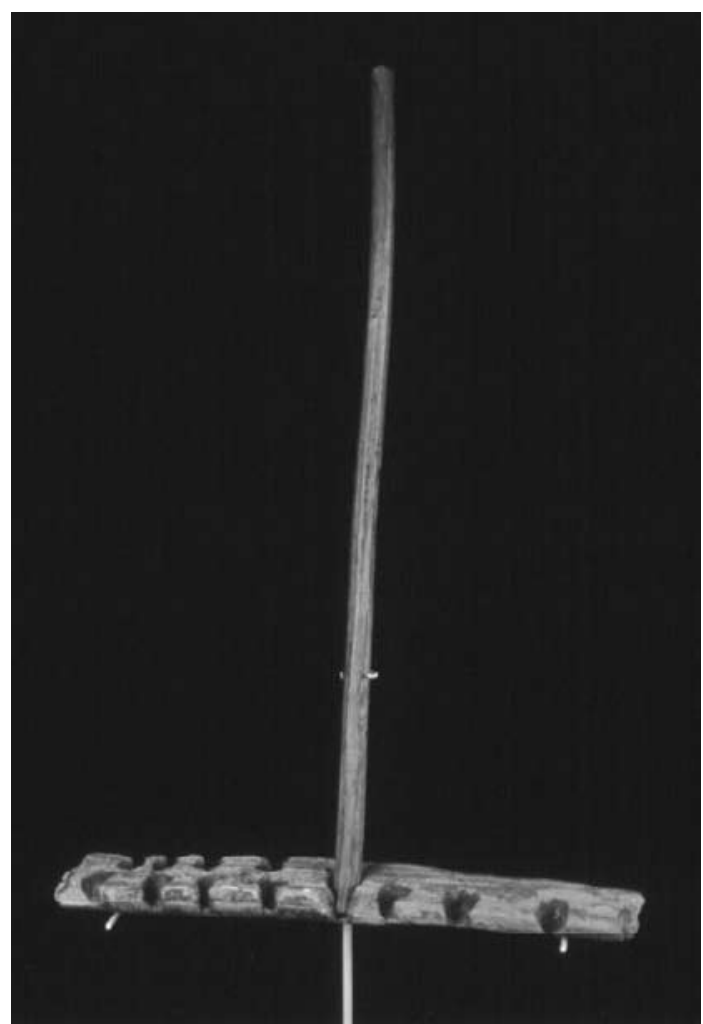

Figura 8. Encendedor de madera, sitio PL. Miller-7. Wood lighter, site PL. Miller-7.

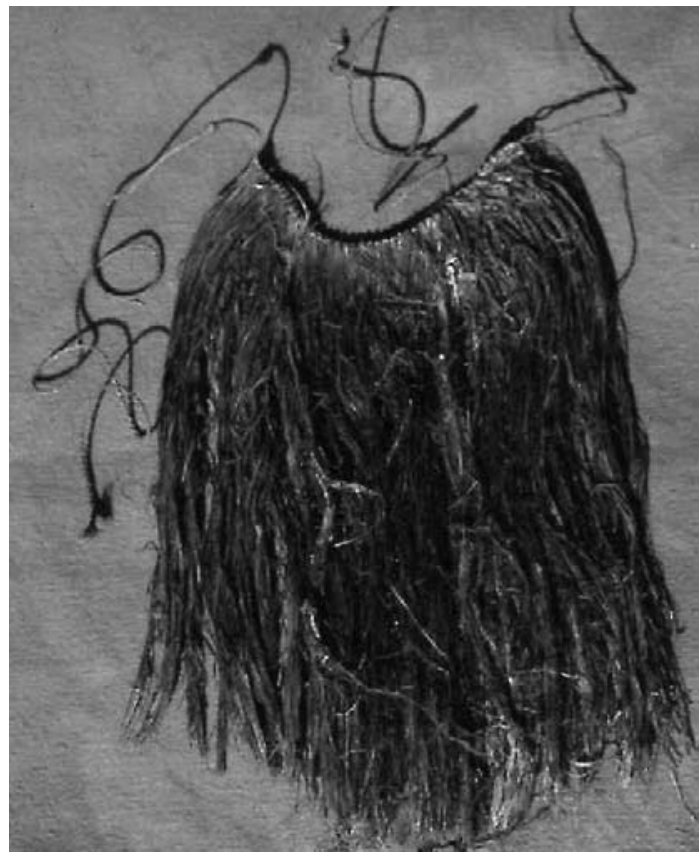

Figura 9. Faldellín de fibra vegetal, sitio cueva La Capilla. Short skirt of vegetable fibre, site La Capilla cave. 


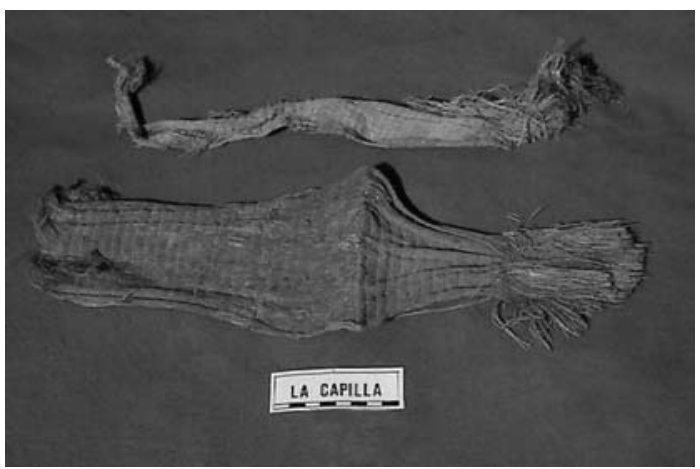

Figura 10. Cobertores púbicos, sitio La Capilla.

Pubic covers, site La Capilla.

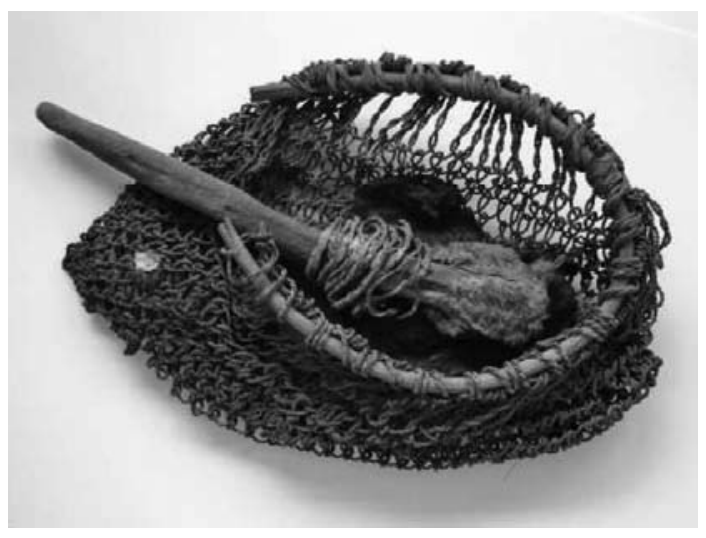

Figura 11. Bolsa confeccionada en fibra vegetal, Complejo Quiani.

Bag made of vegetable fibre, Quiani Complex.

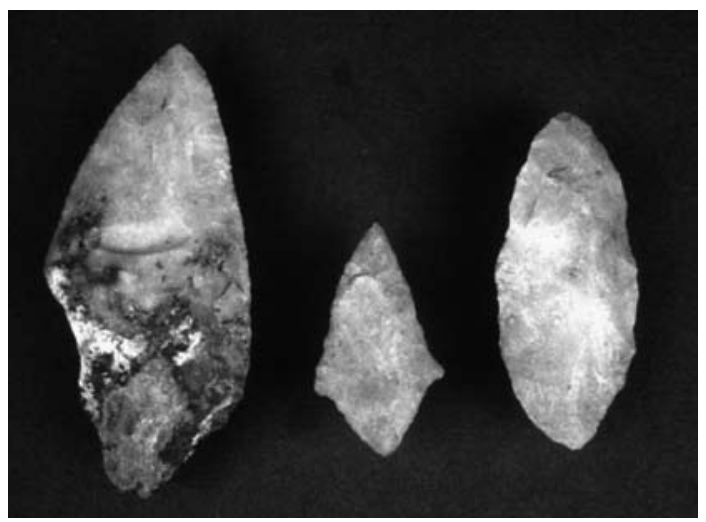

Figura 12. Puntas y cuchillos, sitio Acha-2.

Spikes and knives, site Acha-2.

tipo de puntas de frecuencia menor en relación a las lanceoladas la constituyeron las formas romboidales con aleta y de base pedunculada; estas puntas son frecuentes en el período Arcaico Temprano. Junto a estos artefactos se hallan perforadores y

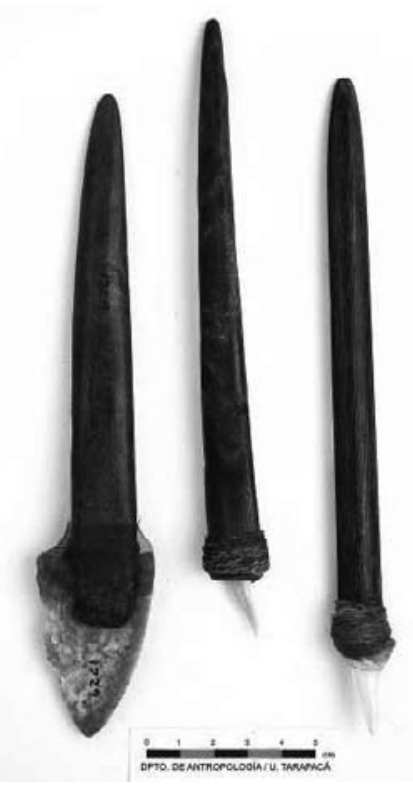

Figura 13. Cuchillos con mango de madera, sitio Morro 2/2. Knives with wood handle, site Morro 2/2.

pulidores, así como instrumentos cortantes como sierra, lascas, láminas y raspadores. Uno de los artefactos de pesca confeccionados en piedra más característicos del período Arcaico son las pesas, las que se caracterizan por dos tipos; las primeras confeccionadas a partir de pequeñas piedras o cantos rodados de $5 \mathrm{~cm}$ de diámetro aproximadamente sin retoque, presentan en la parte central cuerdas de lana, algodón o totora. Las segundas, denominadas "cigarro", tienen un trabajo pulido muy fino. Junto a las pesas se hallaron limas, artefactos que probablemente sirvieron para pulir objetos como anzuelos y cuchillos de concha. El uso de la piedra también está dado en los artefactos de molienda; corresponden a morteros de forma cónica, algunos aparecen asociados a manos de moler, machacadores y canto rodados, otros presentan en su cavidad restos de tierra roja, lo que probablemente indica la molienda de tierras minerales.

Los artefactos confeccionados en hueso se obtuvieron de animales cuyo hábitat fue el desierto costero, así, por ejemplo, las costillas de lobo marino sirvieron para manufacturar instrumentos de extracción de mariscos, también llamados chopes, bastante comunes en el ajuar funerario. También de hueso confeccionaron barbas para anzuelos compuestos y anzuelos para arpón, artefactos usados para las actividades extractivas del mar. Otro artefacto de hueso de forma laminar con uno de sus extremos 
aguzados, al parecer fue utilizado como instrumento de telar o bien como parte de un set del complejo alucinógeno que los pescadores usaban en las ceremonias fúnebres de momificación.

El uso de las conchas en la confección de artefactos constituyó otro de los recursos básicos de las sociedades arcaicas costeras. Uno de los artefactos diagnóstico de la cultura de los pescadores del Arcaico Temprano fue el anzuelo y en menor proporción el cuchillo, ambos confeccionados de conchas de Choromytilus. Las valvas de conchas fueron utilizadas como recipientes para colocar pintura roja; también es posible que hayan cumplido funciones de cucharas para llevar el alimento a la boca, puesto que en varias valvas aparecen restos de alimentos. Asimismo, se manufacturaron pendientes y cuentas de collares en valvas de almejas y caracoles (Olivia peruviana).

Otro de los materiales usados de manera frecuente en los entierros lo constituyen las tierras y minerales, estas fueron usadas tanto para rellenar el cuerpo, así como para pintar la superficie externa de las momias. Por lo general, utilizaban minerales de color rojizo (ocre) o negro (manganeso), además de cenizas de un color blanquecino. En las momias más elaboradas, las llamadas "Momias Negras" (Arriaza 1994; Muñoz et al. 1993; Vera 1981), gran parte del volumen era reconstituido usando una pasta de ceniza y tan sólo la parte externa de la momia era pintada con una delgada capa de manganeso. En algunos casos, los genitales también eran modelados con la pasta de ceniza y parte del órgano del individuo. En cambio, en las "momias rojas" el relleno estaba constituido de varios materiales (fibras, tierras o motas), pero la superficie externa era pintada con ocre rojo, exceptuando la cara, la que a menudo era de un color negro. Por otro lado, para preparar las momias más tardías, con pátina de barro, los Chinchorro usaban una mezcla de tierras con una sustancia adhesiva basada en proteínas, no identificada. Este barro era aplicado homogéneamente sobre todo el cuerpo del individuo, con un revestimiento de $1 \mathrm{a} 2 \mathrm{~cm}$ que, al secarse, quedaba como una cubierta o cemento duro que protegía el cuerpo. Los pigmentos de minerales también fueron utilizados en la confección de pintura rupestre en sitios rituales de la costa de Arica, como es el caso de la cueva de La Capilla donde las figuras fueron pintadas de color rojo (Muñoz y Chacama 1982). Según Figueroa (1982) se trataba de una preparación de óxido de hierro, mezclada con grasa de lobo marino y ceniza. Otros componentes donde se utilizaron tierras arcillosas de temprana data los hallamos en el campamento de Acha-2; allí se hallaron bolones de arcilla cruda mezclada con hojas y restos de fibra vegetal, asociados a las actividades domésticas en dicho campamento (Muñoz y Chacama 1993).

El uso de madera también es frecuente en la confección de yesqueros o encendedores para hacer fuego; también lo fue en la confección de astiles y chopes que servían para la extracción de mariscos y caza de aves (dardos). Las maderas también fueron usadas como refuerzo interno en la preparación de las momias, así por ejemplo, en el caso de las momias rojas o negras, por lo general un madero de aproximadamente $1,5 \mathrm{~cm}$ de diámetro cubría todo el largo de la columna, y otros dos continuaban hacia abajo, uno por cada pierna, hasta los tobillos de la momia, apegados al hueso. También en madera tallaron la figura humana a las cuales los arqueólogos las han denominado "momias estatuillas"; confeccionaron arpones y lanzadardos, objetos que fueron depositados como ofrenda en los entierros. Los arpones, en su mayoría sólo presentan los cabezales desprendibles, que son de unos $20 \mathrm{~cm}$ de largo; los lanzadardos o estólicas tienen un largo aproximado de $40 \mathrm{~cm}$ (Arriaza 2003).

El cabello humano fue utilizado en la confección de pelucas, que eran puestas en la cabeza de las momias. El pelo era torcido en delgadas cuerdas y utilizado como hilo para coser las suturas de las momias o mezclado con lienzas de totora para pescar. En general, este recurso servía para reparar o remendar piezas ya confeccionadas gastadas por el uso, tales como esteras, bolsas y cueros.

En la preparación de las momias observamos el uso de pieles y cueros de mamíferos. En el caso de las primeras, corresponden a pequeños trozos de piel de aves, remendados en sus extremos, presentando restos de pigmentación de color rojo. Posiblemente cumplieron la función de pequeñas bolsas para guardar tierra para colorantes. En algunos casos como en el sitio Morro-1 y otros descritos por Uhle (1919), se observa que también usaban el cuero de las aves para revestir el cuerpo de niños momificados. Las pieles de camélido fueron utilizadas como mortaja, con las que cubrían los cuerpos de los difuntos. La piel del lobo marino a veces era usada para "parchar" las momias, seguramente cuando la piel original no era suficiente. También se colocaban restos de piel de lobo marino en la 
parte posterior y superior de la cabeza, ayudando a sujetar la peluca de las momias. En el tratamiento a las momias se utilizaron pedazos de pieles de cuero de lobo marino en el cuello, tobillos y muñecas a manera de refuerzo, seguramente para evitar su desprendimiento.

El cuero de camélido y de lobo marino también fue usado para confeccionar cobertores púbicos, con los cuales cubrían los genitales de los muertos. Otro uso de cuero se relaciona con la confección de cubiertas para toldos y tiras de amarra usados en los campamentos de la costa como Quiani-9. En otros casos, se utilizó para confeccionar odres, que servían para almacenar agua.

La lana de camélido fue usada entre otros como parte del relleno de las momias Chinchorro. También su uso estuvo dado en la confección de faldellines o cintillos, estos últimos colocados en la cabeza de los difuntos; también confeccionaron cuerdas, hilados y bolsas, en las cuales observamos que los hilados de lana en algunos espacios de las prendas se combinan con hilados de algodón y pelo humano.

Respecto a las plumas, las más usadas corresponden a las de pelícano, se usaban para complementar el relleno de los cuerpos momificados o para cubrir la cara de los cuerpos cuando ya no se practicaba la momificación artificial. Señalemos que el pico de pelícano pintado de rojo fue una ofrenda bastante común en las poblaciones Chinchorro.

También con frecuencia se utilizaron algas (Phaeophyta sp.) que aparecen en los entierros formando rodetes, se usaron para amarrar objetos domésticos y laborales. También se hallan materiales adhesivos orgánicos utilizando una mezcla de proteínas y otros elementos en forma de pasta, tanto para embetunar las momias con pintura roja o negra como para recubrirlas con barro, en el caso de las momias con pátina de barro. Este pegamento, al parecer, fue hecho mezclando diversos materiales como harina de pescado, huevos, sangre y grasa de animal (Figueroa 1991).

La Figura 4 muestra una continuidad en el trabajo de fibra vegetal y madera; las manufacturas en fibra vegetal siguen patrones conocidos desde períodos precerámicos. De juncos y totora confeccionaron su vestuario básico como faldellines y cobertores púbicos, vestimentas típicas de las poblaciones costeras del período Arcaico. Con totora y junquillos confeccionaron hilados para tejer bolsas y cestos y lienzas para pescar (Muñoz 2001); también confeccionaron esteras con las que cubrieron los entierros y cubiertas para toldos. Otras manufacturas de uso doméstico y ceremonial lo constituyeron la cestería coiled y las brochas de base redondeada (Dauelsberg 1985; Focacci y Chacón 1989; Santoro 1982). La manufactura en algodón la componen paños de hilados en torsión $\mathrm{S}$.

El trabajo en hueso es fundamental dentro del acervo cultural de las poblaciones que comienzan a asentarse en el valle. Es interesante mencionar el aumento del uso de la lana de camélido así como el de los artefactos de molienda, esta última como consecuencia de un aumento de la producción agrícola en el valle y de camélidos. La manufactura lítica sigue teniendo importancia, en especial las puntas de forma lanceoladas de gruesos espesores, desapareciendo las de forma romboidal con aleta. Respecto al uso de pelo humano, pieles y colorantes estos fueron utilizados de la misma forma que lo hicieron los grupos arcaicos costeros tanto en ceremonias fúnebres como en el uso doméstico.

En la Figura 5 consideramos los rasgos culturales más representativos por sitios en el contexto de las poblaciones arcaicas y formativas, constituyéndose las manufacturas hechas en hueso, piedra y fibra vegetal en las más representativas de este proceso cultural, quizás en una escala menor y en la medida en que el hombre iba encontrando la línea de cultivo, lo que permitió un proceso aldeano más estable y consolidado, manufacturas como el trabajo en concha fueron perdiendo persistencia.

El análisis de estos rasgos nos permite plantear que estas culturas milenarias no dejaron de manejar los recursos marítimos en la medida que fueron logrando éxito en otras fuentes de subsistencia como la agricultura y ganadería, todo lo contrario, la obtención de recursos a través de estas dos últimas economías la insertaron gradualmente en su desarrollo, sin perder sus antiguas economías de subsistencia. Por lo tanto, en el período Formativo vemos que la complementariedad de recursos fue la base sobre la cual se asentaron los grupos locales.

\section{Interpretación de la Materialidad y Propuestas Finales}

\section{Uso de la materialidad en el contexto del paisaje y la memoria en las poblaciones arcaicas y formativas en la costa de Arica}

La identificación de rasgos culturales confeccionados a través de los distintos recursos que 
ofrece el medio sustenta la hipótesis en cuanto a la optimización que las poblaciones arcaicas hicieron de su entorno. Esta situación implica que conocieron muy bien el medio, tanto costero (litoral), como la desembocadura de ríos y valles circundantes, lo que les permitió hacer un uso racional de la explotación de las especies. El énfasis en la recolección de plantas para la confección de instrumentos y manufacturas sugiere que éste fue un recurso importante en la cultura de las poblaciones pescadoras recolectoras, aunque para la caza marina y terrestre el trabajo en piedra y hueso también cumplió funciones relevantes. La variedad de recursos que proporcionaron los mamíferos marinos, como sus huesos para levantar chozas, la vejiga para almacenar agua, los cueros para abrigo y la carne para alimento, demuestra la importancia de este animal en las poblaciones arcaicas. De igual forma, es destacable el trabajo en concha, en la confección del anzuelo, su uso fue trascendental en la economía de los pescadores arcaicos de los períodos Temprano y Medio. Sin embargo, el conocimiento del espacio no estuvo sólo en lo económico, con la explotación de los recursos para desarrollar tecnologías de subsistencia, sino también en la importancia que tuvieron distintos hitos geográficos en el plano ideológico de estas tempranas sociedades. Así por ejemplo, las vertientes y los cerros constituyeron hitos geográficos trascendentales a partir de los cuales planificaron los asentamientos humanos. De esta manera podríamos pensar que la construcción de basurales con formas de montículos en la costa durante el período Arcaico así como la construcción de montículos en el período Formativo sugiere la idea de construir asentamientos siguiendo la forma de los cerros. Esta idea de integrar los cerros y de hacer de éstos la forma de los asentamientos habitacionales y funerarios nos permite plantear la idea de una trilogía en donde se interrelaciona el paisaje social y natural y el culto a los ancestros conformando una unidad ideológica que fue parte de la identidad de las poblaciones arcaicas y agrícolas tempranas en la costa de Arica.

\section{Campamentos y moradas desde el período Arcaico al Formativo}

Desde los primeros asentamientos costeros vemos que el hombre tuvo un hábitat definido en términos de áreas residenciales, procesamiento y faenamiento de carnes y moluscos y enterramiento de los difuntos. Estas áreas se ubicaban en espacios relativamente cercanos, definiendo de esta manera un hábitat de ocupación humana. En relación a las viviendas más tempranas (7.000 a.C.), éstas se ajustan a un patrón disperso, es decir, separadas varios metros unas de otras. Como se ha dicho, la materia prima utilizada para construir las habitaciones fueron huesos de mamíferos marinos o troncos fundamentalmente de pacae (Inga feuillei) utilizados como soportes de techo y totora para confeccionar las camadas para cubrir sus moradas. Estas viviendas fueron levantadas en sectores donde hubo agua, lo que les permitió obtener fibras vegetales para la confección de prendas de vestir y elaboración de artefactos de trabajo. A partir del 3.000 a.C., los asentamientos habitacionales, manteniendo la misma estructura de los asentamientos más tempranos, crecen en cantidad a consecuencia al parecer de una mayor población, las que habrían logrado una mayor especialización al ambiente costero. Este modelo habitacional de tecnología simple constituye un antecedente interesante pues nos permite concebir que su espacio habitacional tenía un carácter temporal especialmente en los valles como lo demuestran los campamentos de Acha-2 y Conanoxa W a y b.

A finales de la época precerámica los campamentos presentaban viviendas más concentradas, lo que demostraría una acentuada integración grupal entre los pescadores debido tal vez a un mayor aumento demográfico. En las zonas de vertientes como el caso de los Faldeos del Morro, Quiani y la Desembocadura de Camarones, la presencia de entierros asociados a depósitos de basuras sugiere espacios de fuerte articulación social, constituyéndose en campamentos nucleares. En estos lugares hemos hallado una fuerte presencia de fogones y restos de basuras ligados a la preparación de alimentos y acumulación de desperdicios. El espacio de trabajo -áreas de talla lítica-corresponde a sectores abiertos; en el caso específico de las viviendas de Acha-2, la presencia de poliquetos marinos usados en la delimitación de las viviendas nos sugiere elementos transportados de la costa, tal vez con el sentido de señalar el dominio de un espacio territorial. En las basuras hemos hallado restos de huesos y cueros de mamíferos marinos con maderos, todo lo cual nos hace suponer una actividad doméstica desarrollada en sus moradas. La presencia de estos materiales situados sobre fogones nos lleva a plantear la hipótesis de que 
las viviendas fueron levantadas en los depósitos monticulares de basuras - conchales- aprovechando los desniveles de las basuras a manera de depresores con el propósito de que éstos sirvieran de resguardo o protección a un nivel semisubterráneo, colocando una cubierta de fibra vegetal sobre una estructura de madera. Argumentamos esta hipótesis por evidencias halladas en la costa de Arica, en el sitio Quiani-9, donde la base de la pendiente en que se levantó el asentamiento presenta agujeros de postes que siguen una línea circular, sumada a restos de totora, cueros y huesos de mamíferos marinos (Muñoz y Chacama 1982).

El inicio del trabajo agrícola trajo consigo el desplazamiento de las viviendas hacia las tierras cultivadas. Para construir sus moradas los hombres trasladaron materiales de la costa como poliquetos y huesos de mamíferos marinos, los que junto a los arbustos leñosos de especies asteráceas fueron empleados como soportes de techumbres de viviendas. Para cubrir las moradas utilizaron camadas de totora o pieles de animales (guanaco o lobos marinos). Los campamentos construidos por estos pescadores y tempranos agricultores se organizan bajo un espacio abierto para la confección de tecnologías de trabajo, como asimismo un espacio para cobijarse (morada). El campamento Az-115 es un claro ejemplo de estas construcciones. Además presentan el mismo patrón constructivo, en cuanto a su forma y materiales usados, de los hallados en la costa en el período Arcaico, como Acha-2 y Quiani-9. Las evidencias de postes nos sugieren un armazón de forma semicónica, con cubiertas confeccionadas de totora y junquillos. Estos recintos ocuparon los faldeos de cerros y espolones rocosos del valle, lugares de gran visibilidad. El espacio interior de Az-115 muestra evidencias de haber sido ocupado para alimentarse y descansar (Muñoz 2004). A su vez, en los espacios colaterales se observan restos de actividades ligadas con la preparación de objetos. Según Muñoz (2004) AZ-115 nos muestra un campamento construido de material ligero, cuya ubicación en la terraza era modificada constantemente, demostrando por lo tanto una ocupación periódica.

A su vez, en el mismo entorno del emplazamiento habitacional fueron enterrados sus difuntos, lo que denota un espacio de ocupación bien definido. Paralelamente a estas primeras experimentaciones agrícolas comienzan los primeros intentos por preparar arcilla cocida mezclada con fibras vegetales y conchuelas, iniciándose así la tradición alfarería en el valle, vasijas que al parecer tuvieron el propósito para guardar alimentos o líquido.

Respecto a las tecnologías, hemos podido visualizar asociado a los campamentos un importante trabajo de la piedra, que nos permite observar las diferentes etapas de retocado de instrumentos. Por la dispersión que presentan los residuos de material lítico, es posible que su confección pudo haberse realizado fuera de los recintos habitacionales (Muñoz 2004). En estos mismos espacios aparecen con frecuencia morteros con forma de batán y pucos de base cónica; además de cueros remendados con hilados de fibra vegetal y pelo de mamíferos marinos. Otros componentes lo constituyen restos de pieles de mamíferos marinos, vellones e hilados de lana, plumas revestidas con totora, evidencias que nos permiten conocer aspectos del sistema constructivo de las moradas, así como de la confección o reparación de objetos que hacían los tempranos agricultores del valle de Azapa.

\section{Prácticas mortuorias desde el período Arcaico al Formativo}

Los enterramientos más antiguos conocidos hasta la fecha, Acha-2 y Acha-3, indican que dichas poblaciones fueron enterradas en mortajas funerarias -esteras de fibra vegetal- depositándoles ofrendas en el interior de los cuerpos. A los muertos se les cavó una fosa y en el caso de Acha-3 se prepararon entierros colectivos, sin embargo, aún no conocemos que estas poblaciones hayan momificado artificialmente a sus deudos. A partir de los 5.000 a.C. encontramos que los cuerpos de los difuntos fueron tratados con métodos singulares con la idea de conservarlos. Este tratamiento mortuorio estuvo centrado en la evisceración de las cavidades torácica y abdominal, las cuales se rellenaban con materiales diversos como paja, madera, cuero de aves y otros materiales orgánicos para darles volumen hasta llegar a un tratamiento de la superficie de los cuerpos con la intención de reconstruir los individuos. En los cementerios estos cuerpos aparecen enterrados en forma individual y colectiva depositados sobre una gran camada de fibra vegetal. Los entierros colectivos están conformados por recién nacidos niños, jóvenes y adultos de ambos sexos. La presencia de cuerpos restaurados y vueltos a reenterrar indica que los difuntos eran movidos de sus lugares. Su continua remoción indica el cuidado especial que tenían con estas momias, que muestra una unidad 
social preocupada en torno a los ritos de la muerte. Desde el punto de vista social entendemos que estas prácticas mortuorias fueron relevantes dentro del esquema cultural de estos pescadores, pues permitió la armonía e integración entre los componentes del grupo, más aun cuando eran poblaciones que necesitaban de la ayuda mutua para lograr los recursos económicos de subsistencia.

A partir de los 3.000 a.C. se logra el mayor grado de perfeccionamiento en el tratamiento de los cuerpos momificados, destacándose entre otros la elaboración de mascarillas faciales muy estilizadas y pelucas confeccionadas con cabellos humanos. En los entierros se depositaban estatuillas de barro no cocidos, las que también llevaban cabellos humanos a manera de pelucas e iban vestidas con faldellines y cobertores púbicos. En algunos casos, las tumbas aparecen agrupadas, en otros se les construyó una estructura formada por huesos de mamíferos marinos debajo de la cual se depositaron entierros de adultos y párvulos. La presencia de estas tumbas excepcionales nos sugiere que a pesar que estas poblaciones llegaron a tener una organización social sin jerarquías de poder, hallazgos como éstos probablemente correspondan a un grupo de familia donde estuvo enterrado el líder de la banda, lo que implicaría cierto grado de diferenciación social entre los componentes de las bandas de pescadores. A algunos cuerpos que aún se les practicaba la momificación artificial les depositaron como ofrendas pequeñas figuras talladas en madera de tipo antropomorfo, es posible que éstas tuvieran alguna función mágico-religiosa a manera de ídolo, constituyéndose en objetos de prestigio dentro del grupo social. En estos entierros es reiterado el uso de pintura roja en la superficie de los cuerpos, lo que al igual que las figuras de maderas constituiría un elemento simbólico.

A partir del 2.000 a.C. hay modificaciones en el patrón de entierro, así por ejemplo, (a) los cuerpos presentan las piernas extendidas y extremidades que en algunos casos están envueltas en fibra vegetal, (b) los cuerpos están cubiertos por esteras de fibra vegetal y recubiertas de pieles de mamíferos marinos o en su reemplazo camadas de plumas de aves marinas con las cuales cubren totalmente el cuerpo del difunto y (c) algunos cráneos presentan pintura, un agregado facial de pintura roja.

En cuanto a las ofrendas, los mayores objetos fueron elaborados en fibra vegetal, constituyéndose de esta manera en un recurso importante en la cultura de estos tempranos pescadores. El uso de redes y bolsas, así como esteras para cubrir los cuerpos y la confección de vestimentas como faldellines y cobertores púbicos confirman el uso generalizado de la fibra vegetal utilizada por los tempranos grupos costeros. Otros recursos empleados a través del tiempo fueron los colorantes, especialmente el rojo, logrado a través del óxido de hierro, al que en algunos casos se le agregó grasa de lobo marino como ligamento para aplicarla al cráneo de los difuntos como elemento decorativo y en la preparación de las tempranas pinturas rupestres de la cueva de $\mathrm{La}$ Capilla, ubicada en la costa sur de Arica.

En cuanto a los entierros del período agrícola temprano, éstos presentan ciertas similitudes con los del período Arcaico Tardío (2.000 a 1.000 a.C.), cuando ha desaparecido la costumbre de momificar artificialmente los cuerpos. Dichas semejanzas la observamos en la utilización de materiales para estructurar la tumba: la posición de los cuerpos decúbito lateral y dorsal con las piernas flexionadas y las ofrendas que se caracterizan por manufacturas artesanales e instrumentos de trabajo de larga vigencia en el tiempo.

Entre las ofrendas más representativas en cuanto a la materia prima utilizada y tradición tecnológica vinculada con la explotación del mar y caza y recolección terrestre, se halla el trabajo en hueso con el que confeccionaron barbas, pesas, cabezales de arpones, chopes y anzuelos compuestos. De la misma manera, la explotación del recurso vegetal como totora, junquillos, cactáceas y maderas para la confección de vestimenta, esteras, toldos, anzuelos, propulsores, estólicas entre otros, y la calcedonia con la que hicieron una serie de cuchillos y puntas de forma lanceolada, todos ellos son indicadores que la cultura material representativa de las poblaciones costeras se mantuvo en el tiempo a pesar de los cambios generados por la agricultura que pudieron haber implicado que los pescadores se fuesen a vivir al valle de Azapa.

Finalmente, al margen de las moradas y cementerios donde hemos descrito la persistencia de rasgos culturales propios de los pescadores arcaicos y agricultores incipientes, como caso único, tenemos en la costa de Arica un espacio relevante en el contexto ideológico de los pescadores y recolectores; se trata de la cueva de La Capilla, lugar donde según Chacama y Muñoz (1991) se habrían realizado ceremonias de iniciación entre el 800 a.C al 1.700 a.C. La presencia de vestimenta como 
faldellines y cobertores púbicos e instrumentos tecnológicos para la pesca y caza marina, ambos confeccionados con la misma técnica y material de los períodos Arcaico Temprano y Medio, indica que a pesar de los cambios en la estructura económica y social que se estaba generando durante la ocupación de la cueva de La Capilla, la cultura material se mantuvo en cuanto a la utilización de la materia prima así como la forma, técnica y función de los objetos.

De lo anterior, y a manera de síntesis, podemos señalar que a pesar de los cambios culturales llevados a cabo durante la transición de pescadores y recolectores a agricultores incipientes, las evidencias en cuanto a materialidad doméstica y ceremonial no presentan cambios trascendentales, sino más bien éstos se dieron de forma gradual en el tiempo.

\section{Comentarios Finales}

Los medios de subsistencia según Childe (1960) son indicadores del cambio cultural, por lo tanto, la ampliación de la provisión alimenticia fue una condición indispensable del progreso humano. En el caso de la costa de Arica, la tecnología permitió desplegarse y desarrollarse eficientemente dentro de un desarrollo cultural sin grandes interrupciones. Como señala Llagostera (1979), el acceso a la costa fue progresivo y marcó sucesivas conquistas de dimensión física y energética del mar; en el control de cada una de estas conquistas jugaron un importante papel las innovaciones tecnológicas, las que implicaron un mejoramiento de la producción.
Del análisis de los indicadores podemos plantear que las poblaciones locales de tradición costera fueron determinantes en la historia agrícola temprana de los grupos asentados en los valles; los contextos usados en la vida cotidiana de la gente indicarían que al parecer fue una población que se movió con sus propios ejes conductuales, así lo demuestran los indicadores tecnológicos y artesanales que conforman su cultura y que tienen una larga tradición en sus manufacturas y diseños. Esta forma de interactuar que tuvieron las poblaciones locales fue producto de un sistema de organización basada en la complementariedad económica costa-valle, lo cual hizo que tuvieran una movilidad territorial y capacidad para adaptarse, características que las observamos desde los tempranos asentamientos humanos.

Los antecedentes que hemos revisado en torno a la costa de Arica a través de diversos rasgos culturales nos llevan a plantear una larga historia marítima prehispánica, en la cual estuvo inserto el cambio de la sociedad cazadora-recolectora a la sociedad agromarítima, proceso histórico que involucró miles de años, con el consiguiente conocimiento tecnológico especializado al medio: anzuelos de concha y cactáceas, pesas, puntas de arpón, sedales y una estructura social definida formada por bandas como lo demuestran los ritos de momificación que implicaron una organización social cohesionada.

Agradecimientos: Este artículo es producto de la investigación desarrollada en el proyecto Fondecyt 1085106.

\section{Referencias Citadas}

Acuto, F. 2008. Materialidad, espacialidad y vida social: reinterpretando el período Prehispánico Tardío en los Andes del Sur. En Sed Non Satiata II. Acercamientos Sociales en la Arqueología Latinoamericana, compilado por F. Acuto y A. Zarankin, pp. 159193. Ediciones Encuentro Grupo Editor, Córdoba

Álvarez, L. 1969. Un cementerio Precerámico con momias de preparación complicada. Rehue 2:181-190. Actas del IV Congreso Nacional de Arqueología, Concepción.

Allison, M., G. Focacci, B. Arriaza, V. Standen, M. Rivera y L.M. Lowenstein 1984. Chinchorro, momias de preparación complicada: métodos de momificación. Chungara 13:155-173.

Arriaza, B. 1994. Tipologías de momias Chinchorro y evolución de las prácticas de momificación. Chungara 26:11-24.

- - - 2003. Cultura Chinchorro. Las Momias más Antiguas del Mundo. Editorial Universitaria, Santiago.
Aufderheide, A. 1993. Reconstrucción química de la dieta del hombre de Acha. En Acha-2 y Los Orígenes del Poblamiento Humano en Arica, editado por I. Muñoz, M. Arriaza y A. Aufderheide, pp. 65-80. Ediciones Universidad de Tarapacá, Arica.

Bird, J. 1943. Excavation in northern Chile. Anthropological Papers of the American Museum of Natural History XXXVIII, part IV, New York.

Bittmann, B. y J. Munizaga 1976. The earliest artificial mummification in the world? A study of the Chinchorro complex in northern Chile. Saert y Folk 18:61-92. Copenhagen.

Conkey, M. y J. Spector 1984. Archaeology and the Study of Gender. En Advances in Archaeological Method and Theory 7:1-38, editado por M. Schiffer. Academic Press, Inc. 
Childe, G. 1960. Progreso y Arqueología. Editorial Dédalo, Buenos Aires.

Dauelsberg, P. 1974. Excavaciones arqueológicas en Quiani. Chungara 4:7-38.

- - - 1985. Faldas del Morro: Fase Cultural Agroalfarera Temprana. Chungara 14:7-44.

Figueroa, L. 1982. Informe de análisis químico de las pinturas. Documentos de Trabajo 2:194-96, Arica.

- - - 1991. Informe análisis químico de muestra de argamasa. Manuscrito en poder del autor.

Focacci, G. 1974. Excavaciones en Playa Miller 7, Arica (Chile). Chungara 3:23-74.

Focacci, G. y S. Chacón 1989. Excavaciones arqueológicas en los Faldeos del Morro de Arica. Sitios Morro 1/6 y 2/2. Chungara 22:15-62.

Giddens, A. 1990. El estructuralismo, el post-estructuralismo y la producción de la cultura. En La Teoría Social, Hoy, editado por A. Giddens y J. Turner, pp. 254-289. Alianza Editorial, Madrid.

Guillén, S. 1997. Morro 1-5 (Arica) momias y sociedades complejas de los Andes centrales. Boletín de Arqueología PUCP 1:65-78.

Ingold, T. 2000. The Perception of Environment Essays on Livelihood, Dwelling and Skill. Routledge, London and New York.

Kaulicke, P. y T. Dillehay 1999. Introducción ¿por qué estudiar al período Arcaico en el Perú? En El período Arcaico en el Perú, hacia una definición de los orígenes. Boletín de Arqueología PUCP 3:9-18.

Lavallée, D., M. Julien, P. Béarez, P. Usselmann, M. Fontugne y A. Bolaños 1999. Pescadores-recolectores arcaicos del extremo sur Peruano. Excavaciones en la quebrada de los Burros (Tacna, Perú). Bulletin Institute Français d'Etudes Andines 28:13-52.

Lumbreras, L. 1981. Arqueología de la América Andina. Editorial Milla Batres, Lima.

Llagostera, A. 1979. Ocupación humana en la costa norte de Chile asociada a peces local-extintos y a litos geométricos: 9680 \pm 160 A.P. Actas del VII Congreso de Arqueología Chilena, pp. 93-113. Editorial Kultrún, Santiago.

- - - 2003. Patrones de momificación Chinchorro en las colecciones Uhle y Nielsen. Chungara Revista de Antropología Chilena 35:5-22.

Moraga, M., E. Aspillaga, C. Santoro, V. Standen, P. Carvallo y F. Rothhammer 2001. Análisis de ADN mitocondrial en momias del norte de Chile avala hipótesis de origen amazónico de poblaciones andinas. Revista Chilena de Historia Natural 74:711-726.

Muñoz, I. 1980. Investigaciones arqueológicas en los túmulos funerarios del valle de Azapa. Chungara 6:57-95.

- - - 1993. Spatial dimensions of complementary resource utilization at Acha 2 and San Lorenzo. En Domestic Architecture, Ethnicity and Complementary in the South Central Andes, editado por M. Aldenderfer, pp. 94-102. Iowa Press, Iowa.
- - - 2001. Uso de plantas en rituales funerarios del período Formativo en Arica. Chungara Revista de Antropología Chilena 33:155-160.

- - - 2004. Estrategias de Organización Prehispánicas en Azapa: El Impacto de la Agricultura en un Valle del Desierto Costero. Ediciones Universidad de Tarapacá, Arica.

Muñoz, I. y B. Arriaza 2006. Momificación artificial y patrón de residencia de las poblaciones Chinchorro. En El hombre temprano en América y sus implicaciones en el poblamiento de la cuenca de México: Primer Simposio Internacional, coordinado por J. Jiménez, S. Gonzales, J. Pompa y F. Ortiz, pp. 107-144. Colección científica, INAH, México.

Muñoz, I., B. Arriaza y A. Aufderheide 1993. El poblamiento Chinchorro: Nuevos indicadores bioantropológicos y Discusión en torno a su organización social. En Acha 2 y los Orígenes del Poblamiento Humano en Arica, editado por I. Muñoz, B. Arriaza y A. Aufderheide, pp. 107-132. Ediciones Universidad de Tarapacá, Arica.

Muñoz, I. y J. Chacama 1982. Investigaciones arqueológicas en las poblaciones precerámicas de la costa de Arica. Documentos de Trabajo 2:128. Arica.

- - - 1993. Patrón de asentamiento y cronología de Acha-2. En Acha 2 y los Orígenes del Poblamiento Humano en Arica, editado por I. Muñoz, B. Arriaza y A. Aufderheide, pp. 21-46. Ediciones Universidad de Tarapacá, Arica.

Núñez, L. 1969. Sobre los complejos culturales Chinchorro y Faldas del Morro. Rehue 2:111-142.

- - - 1979. Comentario sobre el Área Centro Sur Andina. Departamento de Arqueología, Universidad del Norte, Antofagasta.

- - - 1983. Paleoindio y Arcaico en Chile. Diversidad, Secuencia y Proceso. Series Monografías 3. Ediciones Cuicuilco, México.

- - - 1989. Hacia la producción de alimentos y la vida sedentaria (5.000 a.C a 900 d.C). En Prehistoria de Chile. Desde sus Orígenes Hasta los Albores de la Conquista, editado por J. Hidalgo, V. Schiappacasse, H. Niemeyer, C. Aldunate e I. Solimano, pp. 81-106. Editorial Andrés Bello, Santiago.

Olsen, B. 2003. Material culture after text: Re-membering things. Norwegian Archaeological Review 36:87-104.

Rasmussen, K.A. 1998. Exploring the Origen of Coastal Sedentism in the South-Central Andes. Tesis de Doctorado, University California, Santa Barbara.

Reinhard, K. y V. Dendy 1994. Diet and disease among the Chinchorro: coprolite evidence. Trabajo presentado en el simposio Bioarchaeology of the Chinchorro People. 59 th Annual Meeting of the Society for American Archaeology. Anahein, California.

Rivera, M. 1995. The Preceramic Chinchorro mummy complex of Northern Chile: Context, style and purpose. En Tombs for the Living: Andean Mortuary Practices, editado por T. Dillehay, pp. 43-78. Dumbarton Oaks, Washington DC.

Rivera, M. y F. Rothhammer 1986. Evaluación biológica y cultural de las poblaciones Chinchorro. Nuevos elementos para la hipótesis de contactos transaltiplánicos: Cuenca AmazonasCosta Pacífico. Chungara 16-17:295-306. 
Rothhammer, F., C. Santoro, E. Poulin, B. Arriaza, M. Moraga y V. Standen 2009. Archaeological and mtDNA evidence for Tropical Lowland migrations during the Late Archaic / Formative in northern Chile. Revista Chilena de Historia Natural 82:543-552.

Sagredo R., F. Gutiérrez y P. Aylwin 1998. Geografía de Chile Ilustrada. Santiago.

Shanks, M. y C. Tilley 1987. 1987 Reconstructing Archaeology. Cambridge University Press, New York.

Santoro, C. 1980. Fase Azapa, Transición del Arcaico al desarrollo agrario inicial en los valles bajos de Arica. Chungara 6:46-56.

- - - 1982. Formativo temprano en el extremo norte de Chile. Chungara 8:33-62.

Schiappacasse, V. y H. Niemeyer 1984. Descripción y análisis interpretativo de un sitio Arcaico Temprano en la quebrada de Camarones. Museo Nacional de Historia Natural, Publicación Ocasional 41. Santiago.

Schiappacasse, V., J. Chacama, I. Muñoz y H. Niemeyer 1993. Dispersión del depósito arqueológico en un yacimiento de recolectores arcaicos, con énfasis en el microdepósito. Actas del XII Congreso Nacional de Arqueología Chilena 1991. Tomo I, pp. 1-24, Santiago.

Standen, V. 1991. El Cementerio Morro-1: Nuevas Evidencias de la Tradición Funeraria Chinchorro (Período Arcaico, Norte de Chile). Tesis para optar al grado de Magíster en Arqueología, Pontificia Universidad Católica del Perú, Lima.

Standen, V. y C. Santoro 2004. Patrón funerario arcaico temprano del sitio Acha-3 y su relación con Chinchorro: Cazadores, pescadores y recolectores de la costa norte de Chile. Latin American Antiquity 15:89-109.

Standen, V., C. Santoro y B. Arriaza 2004. Síntesis y propuestas para el período Arcaico en la costa del extremo norte de Chile. Chungara Revista de Antropología Chilena 36, número especial, Tomo I, pp. 201-212.

Sutter, R. 1994. Grupos bioculturales en los valles y costa de Moquegua y Azapa: ¿Verticalidad u horizontalidad? Actas de resúmenes del XII Congreso Nacional de Arqueología Chilena. Antofagasta.

- - - 2006. The test of competing models for the prehistoric peopling of the Azapa valley, Northern Chile, using matrix correlations. Chungara Revista de Antropología Chilena 38:63-82.

Uhle, M. 1919. La arqueología de Arica y Tacna. Boletín de la Sociedad Ecuatoriana de Estudios Históricos Americanos, Quito.

Vera, J. 1981. Momias Chinchorro de Preparación Complicada del Museo Historia Natural de Valparaíso: 3290 y 3060 a.C. Anales del Museo de Historia Natural de Valparaíso 14, Valparaíso.

Wise, K. 1999. Kilómetro 4 y la ocupación del período Arcaico en el área de Ilo, al sur del Perú. Boletín de Arqueología PUCP 3:335-363. 
